\title{
Perfiles de resistencia a antibióticos y metales pesados en Pseudomonas aeruginosa potencialmente patógenas aisladas de agua de uso agrícola Antibiotic and heavy metal resistance profiles in potentially pathogenic Pseudomonas aeruginosa isolated from agricultural water usage
}

Oscar G. Gutiérrez Cárdenas ${ }^{1}$, Luis F. Navarro Ibarra ${ }^{1}$, Pedro D. Loeza Lara ${ }^{1}$, Oscar Guadalupe Del Río Rodríguez ${ }^{1}$ y Rafael Jiménez Mejía ${ }^{1}$

Palabras clave: $P$. eruginosa; virulencia; resistencia a antibióticos; tolerancia a metales

\section{Recepción: 24-04-10 / Aceptación: 24-07-17}

\section{Resumen}

El $70 \%$ del agua a nivel mundial se destina principalmente para las actividades agrícolas. Sin embargo, debido al crecimiento descontrolado de los asentamientos urbanos se ha acentuado la escasez y contaminación de los cuerpos de agua superficiales, de tal forma que cada vez este líquido de buena calidad es más escaso para la agricultura. Uno de los principales contaminantes son las bacterias potencialmente patógenas resistentes a los antibióticos. Pseudomonas aeruginosa es una bacteria que se encuentra normalmente en el agua y suelo, es patógeno de animales y plantas. Esta bacteria se ha considerado un fenómeno de resistencia debido a la diversidad de mecanismos que posee, por lo cual representa un riesgo potencial para la población.

\section{Método}

Se colectaron muestras de agua de uso agrícola, a partir de las cuales se aislaron e identificaron a nivel bioquímico y molecular $P$. aeruginosa. En estas bacterias se determinó la distribución de 6 genes de virulencia por PCR. Mediante ensayos de difusión en disco y microdilución se analizó la resistencia a 20 antibióticos. Además mediante ensayos de microdilución se determinó la resistencia a metales pesados.

\section{Resultados}

Se identificaron a nivel bioquímico y molecular 46 aislados de $P$. aeruginosa, éstas son potencialmente patógenas ya que en ellas se detectó la presencia de los genes de virulencia $\operatorname{alg} D$ y toxA (100\%), lasB (97.8\%), plcH (95.6\%), plcN (91.3\%) y exoS (89.1\%). Dichas bacterias presentaron altos índices de resistencia a ampicilina, ceftriaxona, cloranfenicol, cefalotina, ${ }^{1}$ Universidad de la Ciénega del Estado de Michoacán de Ocampo. Sahuayo, Michoacán. E-mail: rjimenez@ucienegam.edu.mx

@ U Universidad De La Salle Bajío (México) 
cefotaxima, nitrofurantoína, kanamicina, estreptomicina y tetraciclina. De igual forma fueron muy susceptibles a ceftazidima, gentamicina, imipenem, ticarcilina, aztreonam, levofloxacina, netilmicina y carbenicilina. Todas las bacterias fueron multirresistentes ya que toleraron entre $8 \mathrm{y}$ 11 antibióticos. De acuerdo a los patrones de resistencia observados, las bacterias se clasificaron en 11 grupos. Mientras que para los metales pesados se presentaron altos niveles de tolerancia para $\mathrm{Cu}^{+2}, \mathrm{Zn}^{+2}, \mathrm{Ba}^{+2}, \mathrm{~Pb}^{+2}$ y $\mathrm{Se}^{+4}$.

\title{
Conclusión
}

Las $P$. aeruginosa aisladas de agua de uso agrícola en la zona de estudio son potencialmente patógenas debido a la presencia de genes de virulencia. Además presentaron altos índices de resistencia a antibióticos y tolerancia metales pesados.

\begin{abstract}
Seventy percent of water is used in agricultural activities worldwide. However, due to the uncontrolled growth of the population and the contamination of superficial fresh water bodies the water scarcity has augmented, for this the availability of good quality water for agriculture is limited. One of the main pollutants is antibiotic resistant and potentially pathogenic bacteria. $P$. aeruginosa is a bacterium that normally is found in water and soil, it is pathogen from animals and plants. This bacterium has been considered a resistance phenomenon due to the diversity of mechanisms that contain which represent a potential risk to the population.
\end{abstract}

\section{Method}

Samples of agricultural usage water were collected, of which P. aeruginosa was isolates and identified at the biochemical and molecular level. Also, the distribution of virulence genes was analyzed by PCR. The resistance to 20 antibiotics was tested by disk diffusion and microdilution assays. Even more, heavy metal resistance was analyzed by microdilution assays.

\section{Results}

Forty-six $P$. aeruginosa were identified at molecular and biochemical level, the bacteria were potentially pathogenic because the following virulence genes was detected, algD and toxA in $100 \%$ of bacteria, lasB in $97.8 \%$, plcH in $95.6 \%$, plcN in $91,3 \%$ and $\operatorname{exoS}$ in $89.1 \%$. High rates of 
resistance were detected in bacterial isolates for ampicillin, ceftriaxone, chlroramphenicol, cephalotin, cefotaxime, nitrofurantoin, kanamycin, streptomycin and tetracycline. Similarly, susceptibility was detected mainly to ceftazidime, gentamycin, imipenem, tecarcillin, aztreonam, levofloxacin, netilmicin and carbenicillin. All bacteria were multirresistant as they tolerate between 8 and 11 antibiotics. According to the observed resistance patterns bacteria were classified in 11 groups. Whereas, metal tolerance was observed mainly for $\mathrm{Cu}^{+2}, \mathrm{Zn}^{+2}, \mathrm{Ba}^{+2}, \mathrm{~Pb}^{+2}$ y $\mathrm{Se}^{+4}$.

\section{Conclusion}

P. aeruginosa isolated from agricultural usage water samples in the studied zone are potentially pathogenic due to the presence of virulence genes. Even more, high rates of antibiotic and heavy metal resistance were observed.

Keywords: P. eruginosa; virulence; antibiotic resistance; metal resistance. 


\section{Introducción}

La agricultura consume aproximadamente el $70 \%$ del agua a nivel mundial, sin embargo, la creciente demanda del líquido por los centros urbanos e industriales ha disminuido su cantidad y calidad para uso agrícola. En principio, el uso de aguas residuales urbanas presenta beneficios en la agricultura por el ahorro en fertilizantes, debido al alto contenido de nutrientes presentes en ella. No obstante, también tienen desventajas por la presencia de contaminantes, los cuales pueden alterar las propiedades del suelo y representar riesgos a la salud por la presencia de bacterias patógenas (Ensink et al., 2002; Gatica y Cytrin, 2013). De acuerdo con esto último, en los suelos regados con aguas residuales se ha detectado la presencia de bacterias potencialmente patógenas de los géneros Pseudomonas, Stenotrophomonas, Acinetobacter, Escherichia, Klebsiella, Salmonella, Enterococcus y Shigella (Benami et al., 2013; Broszat et al., 2014).

El género Pseudomonas está representado por bacterias de vida libre que habitan principalmente en agua y suelo, en particular, $P$. aeruginosa es de gran interés debido a que es patógena de plantas y humanos, y por sus aplicaciones biotecnológicas potenciales (Silby et al., 2011). P. aeruginosa es un patógeno oportunista de humano siendo las principales infecciones por esta bacteria las de oído, de piel y de heridas, las cuales se adquieren a través del agua; también, es causa frecuente de infecciones en personas con fibrosis quística (Mena y Gerba 2009). Algunos de los factores de virulencia más importantes para el establecimiento y mantenimiento de infecciones por $P$. aeruginosa incluyen la producción de exoproteasas como la elastasa (las $B$ ), fosfolipasas ( $p l c H$ y $p l c N)$, toxinas (exoS y toxA) y producción de polisacáridos (algD) (Faraji et al., 2016).

Por otro lado, los antibióticos se utilizan tanto para el tratamiento de infecciones en humanos como en medicina veterinaria; de igual forma se usan como promotores de crecimiento animal y en acuacultura. Generalmente, estos compuestos se metabolizan parcialmente por los organismos, por lo que el resto termina en los sistemas de agua municipales y aquellos derivados de actividades agropecuarias. Como consecuencia, se ha observado un incremento en la resistencia a los antibióticos por las bacterias ambientales, lo que se ha tornado en un problema ecológico (Kümmerer, 2004). De acuerdo con lo anterior, P. aeruginosa presenta resistencia natural a una gran variedad de antibióticos, además de la capacidad que tiene para adquirir mecanismos adicionales de resistencia a través de elementos genéticos móviles, por lo cual se ha considerado un fenómeno de resistencia a antibióticos (Strateva y Yordanov, 2009; Lutz y Lee, 2011). Por otro lado, se ha observado que la contaminación de ambientes naturales con metales pesados tiene una 
función importante en la evolución, co-selección y distribución de genes de resistencia (BakerAustin et al., 2006). La descarga de metales pesados junto con antibióticos en los cuerpos de agua de los sistemas de agua municipales, de actividades agrícolas o de acuacultura, promueve la coselección de bacterias resistentes a esos compuestos (Seiler y Berendonk, 2012).

El noroeste de Michoacán es una de las zonas importantes en producción agropecuaria del Estado, sin embargo, uno de los principales problemas es la escasez de agua, aunado a la contaminación creciente de los cuerpos de agua superficiales por la mezcla de aguas residuales urbanas e industriales en los ríos y canales de riego. Además, las principales fuentes superficiales utilizadas para el riego de los cultivos en la zona presentan altos niveles de contaminantes químicos (López-Hernández et al., 2007; Sandoval-Moreno y Ochoa-Ocaña, 2010; Equihua et al., 2011). Sin embargo, a la fecha no se tiene conocimiento sobre las bacterias presentes en el agua y sus características de patogenicidad y resistencia. Por lo cual, el objetivo del presente trabajo fue aislar y estudiar la presencia de genes de virulencia así como los perfiles de resistencia a antibióticos y metales pesados en $P$. aeruginosa obtenidas de agua de uso agrícola.

\section{Método}

\section{Aislamiento e identificación de $\boldsymbol{P}$. aeruginosa}

Se colectaron muestras de agua de los canales de riego en la región de la Ciénega de Chapala, Michoacán, en los municipios de Sahuayo ( $20^{\circ} 03^{\prime}$ de latitud norte y $102^{\circ} 43^{\prime}$ de longitud oeste); Venustiano Carranza $\left(20^{\circ} 08^{\prime}\right.$ latitud norte y $102^{\circ} 35$ minutos de longitud oeste); y Vista Hermosa ( $20^{\circ} 16^{\prime}$ de latitud norte y $102^{\circ} 28^{\prime}$ de longitud oeste). Las muestras se colectaron durante los meses de septiembre a diciembre del 2012 a una profundidad de $30 \mathrm{~cm}$ y $1 \mathrm{~m}$ del borde del canal de riego. Se depositaron en tubos estériles y se transportaron en hielo $\left(4^{\circ} \mathrm{C}\right)$ al laboratorio, donde fueron procesadas el mismo día de su colecta. Para la determinación del número total de bacterias viables en las muestras de agua, se hicieron diluciones decimales 1:10, 1:100 y 1:1000; de las últimas dos diluciones se sembraron $100 \mu \mathrm{l}$ en cajas Petri con agar nutritivo (DIBICO). A partir de las colonias crecidas en agar nutritivo se seleccionaron 5 colonias independientes de cada muestra y se sembraron en agar Pseudomonas F. Se seleccionaron las colonias pigmentadas y fluorescentes bajo luz UV, a las cuales se les realizó tinción de Gram y se identificaron bioquímicamente, las

principales pruebas que se realizaron fueron fermentación de glucosa y lactosa, así como 
producción de gas y $\mathrm{H}_{2} \mathrm{~S}$ en agar Kligler con Hierro, IMViC (indol, rojo de metilo, VogesProskauer y citrato), oxidasa y catalasa (MacFaddin, 2000).

\section{Identificación molecular de $\boldsymbol{P}$. aeruginosa}

La confirmación de la identidad de los aislados de $P$. aeruginosa se realizó por PCR de acuerdo con la literatura (Pirnay et al., 2002; Spilker et al., 2004). A partir de un cultivo crecido en agar nutritivo toda la noche se tomó una asada y se resuspendió en $20 \mu 1$ de solución de lisis $(0.25 \%$ de SDS y $0.05 \mathrm{M}$ de $\mathrm{NaOH}$ ). Después, la mezcla se hirvió por $15 \mathrm{~min}$ y se adicionaron $180 \mu \mathrm{l}$ de agua destilada estéril. Las reacciones de amplificación se realizaron en $25 \mu$, conteniendo $1 \mathrm{X}$ Master mix (Promega), $0.5 \mu \mathrm{M}$ de cada primer y $2 \mu \mathrm{l}$ de extracto total de ADN (50 ng aproximadamente). Las condiciones de amplificación con los oligonucleótidos PA-GS-F/PA-GS-R (rDNA 16S) y PASS-F/PA-SS-R (rDNA 16S) (Tabla 1) fueron: un ciclo inicial de desnaturalización a $95^{\circ} \mathrm{C}$ por 5 min, seguido de 30 ciclos de desnaturalización a $94^{\circ} \mathrm{C}$ por $40 \mathrm{~s}$, alineamiento a $55^{\circ} \mathrm{C}$ por $30 \mathrm{~s} \mathrm{y}$ extensión a $72^{\circ} \mathrm{C}$ por 1 min. Las reacciones se terminaron con un ciclo de extensión a $72^{\circ} \mathrm{C}$ por 5 min. Para los primeros PS1/PS1 (oprl) y PAL1/PAL2 (oprL), las condiciones fueron similares a las anteriores, solo que la temperatura de alineamiento fue a $57^{\circ} \mathrm{C}$. Los fragmentos amplificados se separaron en geles de agarosa al 1\%, teñidos con bromuro de etidio y visualizados en un transiluminador Universal Hood (Bio-Rad).

\section{Distribución de genes de virulencia en $\boldsymbol{P}$. aeruginosa}

Para el análisis de la distribución de los genes de virulencia se realizaron amplificaciones por PCR con oligonucleótidos para algD (GDP-manosa 6-deshidrogenasa), lasB (elastasa), toxA (exotoxina A), $p l c H$ (fosfolipasa $\mathrm{C}$ hemolítica), plcN (fosfolipasa C no hemolítica) y exoS (exoenzyme S) de P. aeruginosa (Tabla 1). Las reacciones se realizaron en $25 \mu$ conteniendo $1 \mathrm{X}$ Master mix (Promega), $0.2 \mu \mathrm{M}$ de cada oligonucleótido y $2 \mu \mathrm{l}$ de extracto de ADN. La amplificación de los fragmentos se realizó en las condiciones descritas previamente (Faraji et al., 2016).

\section{Perfil de resistencia a los antimicrobianos}

La resistencia a los antimicrobianos se determinó mediante el método de difusión en agar (CLSI, 2012), para lo cual las bacterias se crecieron en cajas Petri con agar Müeller-Hinton por 20 h a 
Perfiles de resistencia a antibióticos y metales pesados en Pseudomonas aeruginosa potencialmente patógenas aisladas de agua de uso agrícola

$37^{\circ} \mathrm{C}$. A partir de los cultivos de toda la noche se prepararon suspensiones bacterianas en caldo Müeller-Hinton (Difco) a una turbidez equivalente al tubo 0.5 de la escala de McFarland, después $100 \mu 1$ de los cultivos ajustados se sembraron uniformemente sobre la superficie de agar MüellerHinton (Difco). Para este análisis se utilizaron discos (Bio-Rad) impregnados con los siguientes compuestos: amikacina (AK, $30 \mu \mathrm{g}$ ), ampicilina (AM, $10 \mu \mathrm{g}$ ), levofloxacina (LEV, $5 \mu \mathrm{g}$ ), cefalotina $(\mathrm{CF}, 30 \mu \mathrm{g})$, cefotaxima (CTX, $30 \mu \mathrm{g})$, ceftriaxona (CRO, $30 \mu \mathrm{g})$, cloranfenicol (CL, 30

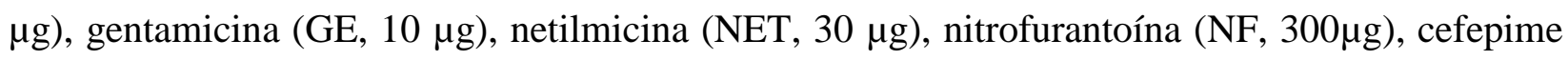
(FEP, $30 \mu \mathrm{g}$ ) y trimetoprim-sulfametoxazol (SXT, $25 \mu \mathrm{g}$ ). También se utilizaron discos de imipenem (IPM, $10 \mu \mathrm{g}$ ), ceftazidima (CAZ, $30 \mu \mathrm{g}$ ), aztreonam (ATM, $30 \mu \mathrm{g}$ ) ticarcilina (TIC, 75 $\mu \mathrm{g}$ ) (DB BBL). Se midió el halo de inhibición y de acuerdo con los valores obtenidos, las bacterias se clasificaron como resistentes, intermedias o sensibles siguiendo los criterios del CLSI (CLSI, 2012). Como control se utilizó la cepa de P. aeruginosa ATCC 27853.

Tabla 1. Oligonucleótidos utilizados en este trabajo.

\begin{tabular}{|c|c|c|c|}
\hline Oligo & Secuencia 5' --- 3' & $\operatorname{Tm}\left({ }^{\circ} \mathrm{C}\right)$ & Fragmento (pb) \\
\hline PS1 & ATGAACAACGTTCTGAAATTCTCTGCT & \multirow{2}{*}{57} & \multirow{2}{*}{249} \\
\hline PS2 & CTTGCGGCTGGCTTTTTCCAG & & \\
\hline PAL1 & ATGGAAATGCTGAAATTCGGC & \multirow{2}{*}{57} & \multirow{2}{*}{504} \\
\hline PAL2 & CTTCTTCAGCTCGACGCGACG & & \\
\hline PA-GS-F & GACGGGTGAGTAATGCCTA & \multirow{2}{*}{54} & \multirow{2}{*}{617} \\
\hline PA-GS-R & CACTGGTGTTCCTTCCTATA & & \\
\hline PA-SS-F & GGGGGATCTTCGGACCTCA & \multirow{2}{*}{58} & \multirow{2}{*}{956} \\
\hline PA-SS-R & TCCTTAGAGTGCCCACCCG & & \\
\hline algD-F & CGTCTGCCGCGAGATCGGCT & \multirow{2}{*}{60} & \multirow{2}{*}{313} \\
\hline algD-R & GACCTCGACGGTCTTGCGGA & & \\
\hline lasB-F & GGAATGAACGAAGCGTTCTCCGAC & \multirow{2}{*}{60} & \multirow{2}{*}{284} \\
\hline lasB-R & TTGGCGTCGACGAACACCTCG & & \\
\hline toxA-F & CTGCGCGGGTCTATGTGCC & \multirow{2}{*}{63} & \multirow{2}{*}{270} \\
\hline toxA-R & GATGCTGGACGGGTCGAG & & \\
\hline plcH-F & GCACGTGGTCATCCTGATGC & \multirow{2}{*}{60} & \multirow{2}{*}{608} \\
\hline plcH-R & TCCGTAGGCGTCGACGTAC & & \\
\hline plcN-F & TCCGTTATCGCAACCAGCCCTACG & \multirow{2}{*}{60} & \multirow{2}{*}{481} \\
\hline plcN-R & TCGCTGTCGAGCAGGTCGAAC & & \\
\hline exoS-F & CGTCGTGTTCAAGCAGATGGTGCTG & \multirow{2}{*}{60} & \multirow{2}{*}{444} \\
\hline exoS-R & CCGAACCGCTTCACCAGGC & & \\
\hline
\end{tabular}




\section{Determinación de la Concentración Mínima Inhibitoria (CMI) a antibióticos}

Con el propósito de expandir el análisis de resistencia a los antibióticos se hicieron ensayos mediante dilución en agar para carbenicilina, kanamicina, estreptomicina y tetraciclina. Para lo cual las bacterias se crecieron en cajas Petri con agar Müeller-Hinton por $20 \mathrm{~h} \mathrm{a} 37^{\circ} \mathrm{C}$. A partir de los cultivos de toda la noche se prepararon suspensiones bacterianas como se indicó en el apartado anterior. Posteriormente, las suspensiones bacterianas se transfirieron a una placa de 48 pozos y con ayuda de un replicador metálico de 48 puntas (V \& P Cientific) se inocularon las suspensiones bacterianas en cajas con las siguientes concentraciones $0,0.25,0.5,1,2,4,8,16,32,64,128,256$, $512 \mu \mathrm{g} / \mathrm{ml}$ de carbenicilina (Sigma), estreptomicina (Sigma), kanamicina (Sigma) y tetraciclina (Sigma). Las cajas se incubaron a $37^{\circ} \mathrm{C}$ por $20 \mathrm{~h}$, la CMI se determinó como la concentración más baja a la cual no se registró crecimiento visible de las bacterias. De acuerdo a los valores de la CMI, los aislados se clasificaron como resistentes o susceptibles. Para carbenicilina se consideraron resistentes los aislados con una $\mathrm{CMI} \geq 512 \mu \mathrm{g} / \mathrm{ml}$, para estreptomicina $\geq 16 \mu \mathrm{g} / \mathrm{ml}$, para kanamicina $\geq 32 \mu \mathrm{g} / \mathrm{ml}$ y para tetraciclina $\geq 16 \mu \mathrm{g} / \mathrm{ml}$ (Salazar et al., 2001; CLSI, 2012).

\section{Concentración mínima inhibitoria a metales}

Para la determinación de la CMI se procedió en la preparación del inoculo de forma similar que para antibióticos. Las bacterias se inocularon en agar nutritivo con las siguientes concentraciones de metales 0. 0.5, 1, 2, 4, 5 y 6 mM de $\mathrm{Cu}^{+2}\left(\mathrm{CuSO}_{4}\right), \mathrm{Zn}^{+2}\left(\mathrm{ZnSO}_{4}\right)$ y Ba ${ }^{+2}\left(\mathrm{BaCl}_{2}\right)$. Para $\mathrm{Hg}^{+2}$ $\left(\mathrm{HgCl}_{2}\right), \mathrm{Ag}^{+1}\left(\mathrm{AgNO}_{3}\right)$ y $\mathrm{Cr}^{+6}\left(\mathrm{~K}_{2} \mathrm{Cr}_{2} \mathrm{O}_{7}\right)$ se probaron concentraciones de $0,0.2$ 0.4, 0. 6, 0.8 y 1 $\mathrm{mM}$; mientras que para $\mathrm{Te}^{+4}\left(\mathrm{~K}_{2} \mathrm{TeO}_{3}\right)$ y Se${ }^{+4}\left(\mathrm{Na}_{2} \mathrm{SeO}_{3}\right)$ se analizaron concentraciones de $0,0.5$, $1,2,4,5,6,7,8,9,10,12,14,16,18$ y $20 \mathrm{mM}$. Las cajas se incubaron por $24 \mathrm{hrs}$ a $37^{\circ} \mathrm{C}$, transcurrido el tiempo se observaron y se registró la CMI, es decir la concentración a la que ya no se observó crecimiento.

\section{Resultados}

\section{Aislamiento e identificación de $\boldsymbol{P}$. aeruginosa}

Durante septiembre a diciembre del 2012 se colectaron 20 muestras de agua de fuentes superficiales destinadas al uso agrícola en el noroeste del estado de Michoacán, México. Los resultados 
obtenidos de bacterias viables presentes en las muestras de agua oscilaron entre $2 \times 10^{4}$ y $1.2 \times 10^{6}$ UFC/ml. A partir de 100 colonias seleccionadas al azar se estudiaron con más detalle 46 aislados que mostraron pigmentación verde y producción de fluorescencia bajo luz UV en agar Pseudomonas F. La identidad de las bacterias fue confirmada a nivel bioquímico donde se observó que no fermentaron lactosa ni glucosa y no produjeron gas ni $\mathrm{H}_{2} \mathrm{~S}$ en agar Kligler con Hierro, también en INViC dieron (---+), crecieron en agar cetrimida, positivos para oxidasa y catalasa, producción de piocianina y fluoresceina. Las 46 bacterias fueron confirmadas a nivel molecular como P. aeruginosa mediante la amplificación de los genes oprI/oprL (Pirnay et al., 2002) y de fragmentos específicos del gen ribosomal 16S a nivel de género y especie (Spilker et al., 2004).

\section{Distribución de genes de virulencia}

Con el propósito de analizar el potencial de virulencia de los aislados bacterianos se determinó la distribución de 6 genes importantes para la virulencia en las 46 P. aeruginosa, se encontró que los más frecuentes fueron tox $A$ y $\operatorname{alg} D$ detectados en las 46 bacterias, los cuatro genes restantes se identificaron como sigue; las $B$ en 45, plcH en 44, plcN en 42, exoS en 41.

\section{Análisis de resistencia a los antibióticos}

Los datos obtenidos de susceptibilidad de las $46 P$. aeruginosa contra 16 antibióticos mediante difusión en disco, indicaron que los mayores índices de resistencia se registraron para ampicilina, ceftriaxona y cloranfenicol con el 100\% de aislados resistentes, seguido del $97.8 \%$ de resistentes a cefalotina, 93.5\% a cefotaxima y nitrofurantoína, respectivamente; mientras que $47.8 \%$ fue resistente a trimetoprim-sulfametoxazol (Tabla 2). Por otro lado, todas las P. aeruginosa fueron susceptibles a ceftazidima, gentamicina, imipenem y ticarcilina, mientras que para amikacina, aztreonam, levofloxacina y netilmicina el $97.8 \%$ fue susceptible. También, altos índices de susceptibilidad se registraron para netilmicina $95.7 \%$ y cefepima con el 73.9\% (Tabla 2).

$\mathrm{El}$ análisis de la CMI mostró que todas las bacterias tuvieron una CMI $\geq 32$ y $\leq 128 \mu \mathrm{g} / \mathrm{ml}$ para carbenicilina, para kanamicina entre $\geq 128 \mathrm{y} \leq 256 \mu \mathrm{g} / \mathrm{ml}$, para estreptomicina de entre $\geq 16 \mathrm{y}$ $\leq 64 \mu \mathrm{g} / \mathrm{ml}$ y por último para tetraciclina de $64 \mu \mathrm{g} / \mathrm{ml}$ (Tabla 3). De acuerdo a estos resultados las bacterias que se inhibieron en concentraciones menores a las indicadas por la línea punteada se consideraron susceptibles y las que su CMI está por arriba de la línea se consideraron resistentes (Salazar et al., 2001; CLSI, 2012). 
Tabla 2. Resultados del análisis de resistencia de $P$. aeruginosa contra 16 antibióticos.

\begin{tabular}{lccc}
\hline & \multicolumn{3}{c}{ P. aeruginosa } \\
\cline { 2 - 4 } Antibiótico & $\mathbf{R}(\%)^{*}$ & I (\%) & S (\%) \\
\hline Amikacina (Ak) & $1(2.2)$ & - & $45(97.8)$ \\
Ampicilina (Am) & $46(100)$ & - & - \\
Aztreonam (Atm) & - & $1(2.2)$ & $45(97.8)$ \\
Cefalotina (Cf) & $45(97.8)$ & - & $1(2.2)$ \\
Cefepima (Fep) & $6(13)$ & $6(13)$ & $34(73.9)$ \\
Cefotaxima (Ctx) & $43(93.5)$ & $2(4.3)$ & $1(2.2)$ \\
Ceftazidima (Caz) & - & - & $46(100)$ \\
Ceftriaxona (Cro) & $46(100)$ & - & - \\
Cloranfenicol (Cl) & $46(100)$ & - & - \\
Gentamicina (Ge) & - & - & $46(100)$ \\
Imipenem (Ipm) & - & - & $46(100)$ \\
Levofloxacina (Lvx) & $1(2.2)$ & - & $45(97.8)$ \\
Netilmicina (Net) & $2(4.3)$ & - & $44(95.7)$ \\
Nitrofurantoína (Nf) & $43(93.5)$ & $1(2.2)$ & $2(4.3)$ \\
Ticarcilina (Tic) & - & - & $46(100)$ \\
Trimetoprim-Sulfametoxazol (Sxt) & $22(47.8)$ & $22(47.8)$ & $2(4.3)$ \\
\hline
\end{tabular}

$* \mathrm{R}$, resistente; I, resistente intermedia; $\mathrm{S}$, sensible.

Tabla 3. Concentraciones Mínimas Inhibitorias de antibióticos.

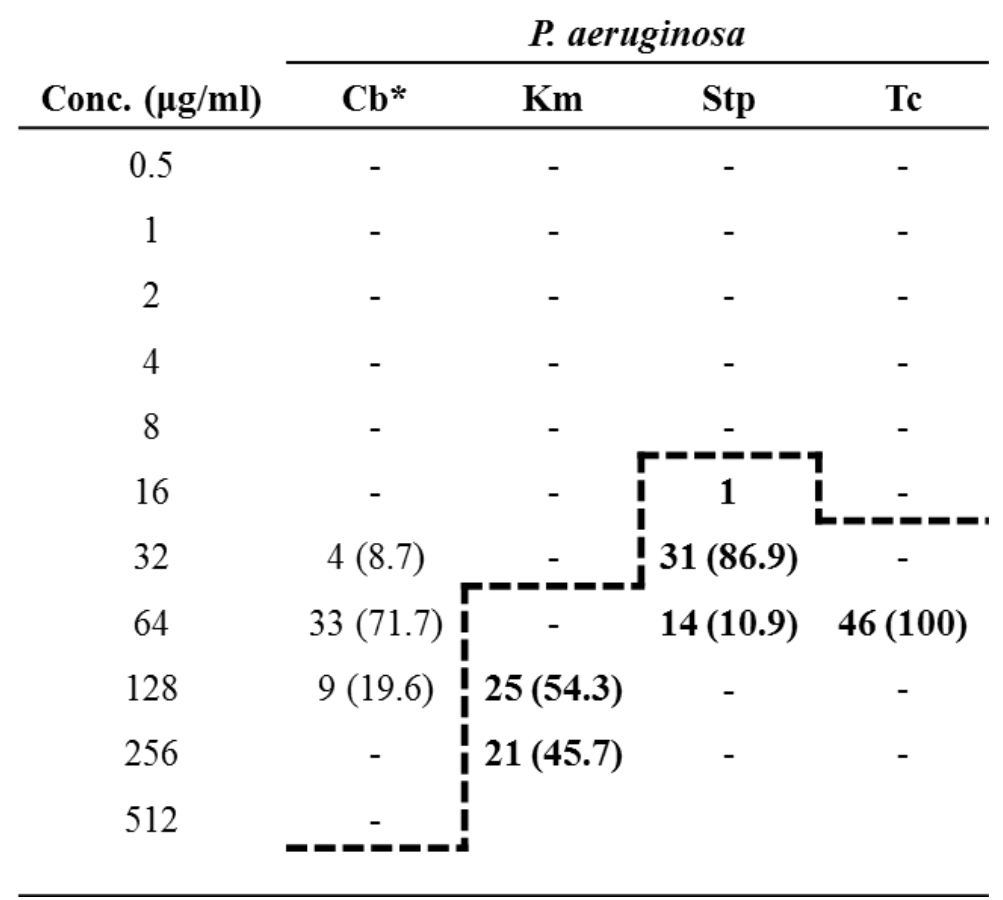

*Cb, Carbenicilina; Km, kanamicina; Stp, estreptomicina; Tc, tetreciclina. 


\section{Perfiles de resistencia}

El análisis de los perfiles de resistencia mostró que las $46 P$. aeruginosa se agruparon en 11 patrones de resistencia que van desde los 8 hasta los 11 antibióticos. De las cuales el $43.5 \%$ resistió 9 antibióticos, $39.1 \%$ resistió 10 compuestos, $10.9 \%$ resistió 11 antibióticos y $6.5 \%$ resistió 8 compuestos. Los dos patrones más frecuentes fueron los de resistencia a 9 antibióticos (AmCfClCroCtxKmNfStpTc) con 18 bacterias y el de resistencia a 10 antibióticos (AmCfClCroCtxKmNfStpStxTc) con 15 bacterias (Tabla 4).

Tabla 4. Patrones de resistencia de $P$. aeruginosa contra 20 antibióticos analizados.

\begin{tabular}{lcc}
\hline \multicolumn{1}{c}{ Perfil de resistencia* } & No. aislados & No. antibióticos \\
\hline AmCfClCroCtxKmStpTc & 1 & \\
AmCfClCroKmNfStpTc & 1 & 8 \\
AmClCroKmLevNfStpTc & 1 & \\
AmCfClCroCtxKmNfStpTc & 18 & 9 \\
AmCfClCroCtxKmStpStxTc & 1 & \\
AmCfClCroFepKmStpStxTc & 1 & 10 \\
AmCfClCroCtxKmNfStpStxTc & 15 & \\
AmCfClCtxCroKmNetNfStpTc & 2 & 11 \\
AmCfClCroCtxFepKmNfStpTc & 1 & \\
AmCfClCroCtxFepKmNfStpStxTc & 4 & \\
AkAmCfClCroCtxKmNfStpSxtTc & 1 & \\
\hline
\end{tabular}

*Abreviaciones: Ak amikacina, Am ampicilina, Cf cefalotina, $\mathrm{Cl}$ cloranfenicol, Cro ceftriaxona, Ctx cefotaxima, Fep cefepima, Ge gentamicina, Km kanamicina, Lev levofloxacina, Net netilmicina, Nf nitrofurantoína, Stp estreptomicina, Sxt trimetoprima-sulfametoxazol, Te tetraciclina.

\section{Tolerancia a metales pesados}

Se encontró que las $P$. aeruginosa mostraron tolerancia principalmente a $\mathrm{Cu}^{+2}, \mathrm{Zn}^{+2}, \mathrm{Ba}^{+2}$ y $\mathrm{Se}^{+4}$. En este sentido, para $\mathrm{Cu}^{+2}$ la CMI más alta fue de $3 \mathrm{mM}$ en el $82.6 \%$ de las bacterias; mientras que para $\mathrm{Zn}^{+2}$, la CMI más alta fue de $6 \mathrm{mM}$ en el $47.8 \%$ de las bacterias; para el $\mathrm{Ba}^{+2}$, la mayor CMI fue de $4 \mathrm{mM}$ en el 21.7\%; para $\mathrm{Pb}$, la CMI fue de $2.5 \%$ en el $100 \%$ y por último; para $\mathrm{Se}^{+4}$, el $100 \%$ de las bacterias toleró hasta una concentración de $20 \mathrm{mM}$. Por otro lado, las bacterias mostraron susceptibilidad para $\mathrm{Cr}^{+6}, \mathrm{Hg}^{+2}, \mathrm{Ag}^{+2}, \mathrm{y} \mathrm{Te} \mathrm{Te}^{+4}$ (Tabla 5). 
Tabla 5. CMI de las $P$. aeruginosa frente a diversos metales.

\begin{tabular}{ccc}
\hline Metal & CMI $(\mathbf{m M})$ & No. aislados \\
\hline $\mathrm{Cu}^{+2}$ & 2 & 8 \\
& 3 & 38 \\
& 3 & 4 \\
$\mathrm{Zn}^{+2}$ & 4 & 6 \\
& 5 & 14 \\
& 6 & 22 \\
$\mathrm{Cr}^{+6}$ & 0.1 & 10 \\
& 0.2 & 36 \\
$\mathrm{Hg}^{+2}$ & 0.02 & 46 \\
$\mathrm{Ba}^{+2}$ & 3 & 36 \\
$\mathrm{Ag}^{+1}$ & 4 & 10 \\
$\mathrm{~Pb}^{+2}$ & 0.1 & 46 \\
$\mathrm{Se}^{+4}$ & 2.5 & 46 \\
$\mathrm{Te}^{+4}$ & $>20$ & 46 \\
\hline & 0.5 & 46 \\
\hline
\end{tabular}

\section{Discusión o Conclusiones}

El riego agrícola con agua de mala calidad, por ejemplo mezcladas con aguas residuales domésticas, tiene la ventaja de proporcionar materia orgánica al suelo. Sin embargo, esto también contribuye al desarrollo de microorganismos tanto nativos del suelo como de aquellos presentes en el agua, modificando así sus poblaciones (Broszat et al., 2014).

$P$. aeruginosa es una bacteria que comúnmente se encuentra en el agua residual doméstica, suelos agrícolas y drenajes de corrales (Mena y Gerba, 2009). De acuerdo con esto, en este trabajo se encontró que de 100 bacterias seleccionadas al azar 46 se identificaron como P. eruginosa, ya que todas las muestras fueron positivas para esta bacteria. Esto concuerda con lo reportado en la literatura en donde se ha observado que $P$. aeruginosa es una bacteria ubicua en sistemas acuáticos contaminados (Mena y Gerba, 2009). La presencia de este tipo de bacterias en agua de uso agrícola representa riesgos potenciales para las personas que entren en contacto con ésta, como los agricultores, ya que en todas las bacterias se detectó alta frecuencia de genes de virulencia importantes durante el proceso infeccioso; algD y toxA (100\%), lasB (97.8\%), plcH (95.6\%), plcN $(91.3 \%)$ y $\operatorname{exoS}(89.3 \%)$. Estos resultados concuerdan en parte con lo reportado por Pitondo-Silva et al. (2016), quienes identificaron diversos genes de virulencia en P. aeruginosa aisladas de suelo y encontraron que los más frecuentes fueron $\operatorname{lasB}(76 \%)$, plcH $(74 \%)$ y $\operatorname{algD}(52 \%)$. En otro estudio se encontró que $P$. aeruginosa aisladas de muestras de agua para beber mostraron 
prevalencia de genes de virulencia como sigue exoS (20.9\%), ecfX (100\%), exoS (97.7\%), phzM (93\%), toxA (93\%) y lasB (100\%) (Wu et al., 2016).

Por otro lado, el uso de antibióticos tanto en humanos como en animales ha incrementado la concentración de estos compuestos en los cuerpos de agua, lo cual trae como consecuencia un incremento en el surgimiento de bacterias resistentes a esos compuestos (Zhang et al., 2009). De tal forma que la descarga en aguas residuales tanto domésticas como de origen agropecuario favorece la co-selección de bacterias resistentes a antibióticos y metales pesados (Seiler y Berendonk, 2012). En este sentido los aislados de P. aeruginosa fueron multirresistentes ya que resistieron entre 8 y 11 compuestos distintos, de acuerdo con esto se clasificaron en 11 patrones de resistencia a antibióticos. Se ha reportado que las $P$. aeruginosa presentan altos niveles de resistencia tanto intrínseca como adquirida a diversos antibióticos (Strateva y Yordanov, 2009). Además, otros autores han reportado multirresistencia en $P$. aeruginosa aislada de muestras colectadas de plantas tratadoras de aguas residuales, en donde se encontró que las bacterias presentaron resistencia de 5 a 11 antibióticos destacando la resistencia a compuestos betalactámicos (100\%) (Odjadjare et al., 2012). De igual forma, se ha encontrado resistencia a antibióticos en $P$. aeruginosa aislada de muestras de agua de piscinas y jacuzzi. Los autores reportan que el $96 \%$ de las bacterias estudiadas fueron multirresistentes principalmente a los compuestos anti-Pseudomonas de uso clínico (Lutz y Lee, 2011).

Asimismo, las bacterias analizadas en este trabajo mostraron resistencia a los metales $\mathrm{Cu}$, $\mathrm{Zn}, \mathrm{Pb}, \mathrm{Ba}$ y $\mathrm{Se}$ lo cual concuerda con lo previamente observado que la presencia de metales pesados favorece la selección o co-selección de bacterias resistentes a los antibióticos (Seiler y Berendonk, 2012). En este sentido se ha observado que aislados de P. aeruginosa resistentes a metales pesados obtenidas de muestras de suelo mostraron resistencia a antibióticos, lo cual confirma diversas observaciones que indican la co-selección de ambos mecanismos de resistencia (Pitondo-Silva et al., 2016).

En conclusión, de acuerdo con los resultados presentados se encontró que las $P$. aeruginosa presentes en el agua de uso agrícola en el área de estudio representan un gran riesgo para la salud de las personas por la presencia de genes de virulencia, y por la multirresistencia a los antibióticos que se encontró en estos aislados. Además, las bacterias multirresistentes a los antibióticos también presentaron resistencia a metales pesados, lo cual sugiere que el medio acuático estudiado favorece la co-selección de estos fenómenos. 


\section{Agradecimientos}

A la Universidad de La Ciénega del Estado de Michoacán de Ocampo, por el financiamiento y facilidades brindados para el desarrollo del presente trabajo.

\section{Referencias}

Baker-Austin, C., Wright, M. S., Stepanauskas, R., McArthur, J. V. (2006). Co-selection of antibiotic and metal resistance. Trends in Microbiology, 14(4), 176-182.

Benami, M., Gross, A., Herzberg, M., Orlofsky, E., Vonshak, A., Gillor, O. (2013). Assessment of pathogenic bacteria in treated graywater and irrigated soils. Science of the Total Environment, 458, 298-302.

Broszat, M., Nacke, H., Blasi, R., Siebe, C., Huebner, J., Daniel, R., Grohmann, E. (2014). Wastewater irrigation increases the abundance of potentially harmful Gammaproteobacteria in soils in Mezquital Valley, Mexico. Applied and Environmental Microbiology, 80(17), 5282-5291.

CLSI, Clinical and Laboratory Standards Institute, 2012: M2-A11: Performance Standards for Antimicrobial Disk Susceptibility Test: Approved Standard- Eleventh Edition. Clinical Laboratory Standards Institute, Wayne, PA.

Equihua-Pimentel JL, Velázquez-Machuca MA, Sánchez-Rodríguez M, Seefoó-Luján JL. Gestión y calidad del agua en la cuenca del río Duero, Michoacán. En: Spring OU. Coordinadora. Retos de la investigación del agua en México. Cuernavaca, México, CRIM-UNAM. 2011. p. 521-530.

Faraji, F., Mahzounieh, M., Ebrahimi, A., Fallah, F., Teymournejad, O., Lajevardi, B. (2016). Molecular detection of virulence genes in Pseudomonas aeruginosa isolated from children with Cystic Fibrosis and burn wounds in Iran. Microbial Pathogenesis, 99, 1-4.

Gatica, J., Cytryn, E. (2013). Impact of treated wastewater irrigation on antibiotic resistance in the soil microbiome. Environmental Science and Pollution Research, 20(6), 3529-3538.

Ensink, J. H., Van Der Hoek, W., Matsuno, Y., Munir, S., Aslam, M. R. (2002). Use of untreated wastewater in peri-urban agriculture in Pakistan: Risks and opportunities. International Water Management Institute, 64, 1-22.

Kümmerer, K. (2004). Resistance in the environment. Journal of Antimicrobial Chemotherapy, 54(2), 311-320.

No 19, Vol. 9 (2), 2017. ISSN 2007 - 0705, pp.: 97 - 112 
Perfiles de resistencia a antibióticos y metales pesados en Pseudomonas aeruginosa potencialmente patógenas aisladas de agua de uso agrícola

López-Hernández M, Ramos-Espinosa MG, Carranza-Fraser J. (2007). Análisis multimétrico para evaluar contaminación en el río Lerma y lago de Chapala, México. Hidrobiológica, 7:1730.

Lutz, J. K., Lee, J. (2011). Prevalence and antimicrobial-resistance of Pseudomonas aeruginosa in swimming pools and hot tubs. International Journal of Environmental Research and Public Health, 8(2), 554-564.

MacFaddin JF. Pruebas bioquímicas para la identificación de bacterias de importancia clínica, $3^{\text {a }}$ edición, Montevideo, Uruguay, Panamericana, 2000.

Mena, K. D., Gerba, C. P. (2009). Risk assessment of Pseudomonas aeruginosa in water. In Reviews of Environmental Contamination and Toxicology, 201, 71-115.

Odjadjare, E. E., Igbinosa, E. O., Mordi, R., Igere, B., Igeleke, C. L., Okoh, A. I. (2012). Prevalence of multiple antibiotics resistant (MAR) Pseudomonas species in the final effluents of three municipal wastewater treatment facilities in South Africa. International Journal of Environmental Research and Public Health, 9(6), 2092-2107.

Pirnay, J. P., De Vos, D., Cochez, C., Bilocq, F., Vanderkelen, A., Zizi, M., Ghysels, B., Cornelis, P. (2002). Pseudomonas aeruginosa displays an epidemic population structure. Environmental Microbiology, 4(12), 898-911.

Pitondo-Silva, A., Gonçalves, G. B., Stehling, E. G. (2016). Heavy metal resistance and virulence profile in Pseudomonas aeruginosa isolated from Brazilian soils. APMIS, 124(8), 681-688.

Salazar, D., Hernández, Y., Palma, S., González, A., Reyes, T. (2001). Actividad antimicrobiana de doce fármacos frente a cepas de Pseudomona aeruginosa de origen clínico. Bioquimia, 26(4), 79-84.

Sandoval-Moreno, A., \& Ochoa-Ocaña, M. A. (2010). Grupos locales, acceso al agua y su problemática de contaminación en la ciénega de Chapala, Michoacán. Economía, Sociedad y Territorio, 10(34), 683-719.

Seiler, C., Berendonk, T. U. (2012). Heavy metal driven co-selection of antibiotic resistance in soil and water bodies impacted by agriculture and aquaculture. Frontiers in Microbiology, 3:399.

Silby, M. W., Winstanley, C., Godfrey, S. A., Levy, S. B., Jackson, R. W. (2011). Pseudomonas genomes: diverse and adaptable. FEMS Microbiology Reviews, 35(4), 652-680. 
Spilker, T., Coenye, T., Vandamme, P., LiPuma, J. J. (2004). PCR-based assay for differentiation of Pseudomonas aeruginosa from other Pseudomonas species recovered from cystic fibrosis patients. Journal of Clinical Microbiology, 42(5), 2074-2079.

Strateva, T., Yordanov, D. (2009). Pseudomonas aeruginosa-a phenomenon of bacterial resistance. Journal of Medical Microbiology, 58(9), 1133-1148.

Wu, Q., Ye, Y., Li, F., Zhang, J., Guo, W. (2016). Prevalence and genetic characterization of Pseudomonas aeruginosa in drinking water in Guangdong Province of China. LWT-Food Science and Technology, 69, 24-31.

Zhang, XX, Zhang T, Fang HHP. Antibiotic resistance genes in water environment. Applied Microbiology and Biotechnology, 2009; 82:397-414. 